\title{
Effect of Foam Copper Interlayer on the Mechanical Properties and Fretting Wear of Sandwich Clinched Joints
}

\author{
Lei Lei ${ }^{1)}$, Xiaocong $\mathrm{He}^{1)}{ }^{1)}$, Baoying Xing ${ }^{1)}$, Desuo Zhao ${ }^{1)}$, Fengshou $\mathrm{Gu}^{2)}$, Andrew Ball ${ }^{2)}$
}

1) Innovative Manufacturing Research Centre, Kunming University of Science and Technology, Kunming, 650500, PRC

2) Centre for Efficiency and Performance Engineering, University of Huddersfield, Queensgate, Huddersfield, HD1 3DH, UK.

\begin{abstract}
Fretting wear has a considerable effect on the fatigue properties of clinched joints and is the most important cause of fatigue failure in them. Foam metal is a new type of structural material that can be sandwiched into a clinched joint to improve its mechanical properties with respect to fretting wear.

In the work reported here, clinched single-lap and cross-lap joints with and without foam copper layers were prepared and subjected to static load testing. Fatigue tests were conducted on the single-lap joints to analyse the fatigue properties and failure modes of the aluminium-alloy clinched and foam metal sandwich clinched joints. The damage caused in single-lap joints by fretting wear was assessed by examining joint cross-sections before completely fatigue broken. Scanning electron microscopy and energy spectrometry were used to examine the failure fractures of the two kinds of joints and to investigate the fretting wear failure mechanism. The incorporation of the foam copper layer increased the shear strength of the clinched joint by $5 \%$ but had little effect on the peeling strength. It also increased the energy absorption capacity of the joint under a shear force by $33 \%$, but reduced it under a peeling load by $27 \%$.

The fretting wear of the clinched joint occurred mainly at the contact surface of the two sheets in the lap area and at the clinched neck. Fretting wear generated oxide wear debris and caused micro-cracks on the sheet surface and these micro-cracks then continuously expanded until sheet fracture failure occurred.

The foam copper layer effectively reduced the fretting wear between the upper and lower sheets and greatly enhanced the fatigue life of the aluminium-alloy clinched joint.
\end{abstract}

Key words: clinching; fretting wear; foam copper; sandwich structure 


\section{Introduction}

Clinching (He 2017) is a new type of cold-forming technology for joining materials together. In the clinching process, the punch and die force the material between them to flow so as to form a frictional interlocking connection point. Clinching has the advantage of being lightweight because no rivets are needed. This results in much lower production costs than for rivet-based joining methods, especially in industrial scale applications. Although the static strength of clinched joints is lower than for those using self-piercing riveting (SPR) or spot welding for the same material, its fatigue performance is better because of the mechanical structure of the joint. In addition, the clinching process is easy to automate and can be used to solve some problems with dissimilar materials, plated material, and multilayer material connections. Also, there are no exhaust emissions during the connection process. Varis $(2002,2003)$ studied the effect of circular and rectangular moulds on clinched joint strength and derived a procedure for selecting an appropriate mould using finite element analysis. Paula et al. (2007) studied the effect of varying process parameters on the static strength of clinched joints. They observed and reported on the microscopic stress distribution of the plastic deformation zone. Mucha (2011) analysed the forces operating in the joint interlocking zone under a tensile-shear and peeling force and compared the joint strengths fot spot welding and clinching. Spisak et al. (2012) evaluated the clinched joints properties used in car body production for the microalloyed steel H220PD, the high strength steel TRIP 40/70+Z100MBO and the drawing grade steel DX51D+Z. Lambiase et al. (2015) reduced the forming stress and found that reducing the depth of the lower die, changing the shape of the punch, and preheating the material, improved the performance of clinched connections in AA6082T6 aluminium alloy sheet. Chen et al. (2016) proposed a new clinching technique using a rivet to reshape the clinched joints. This enabled the height of the clinched point to be reduced and improved the joint strength. He et al. (2017) dealt with the mechanical properties and fracture analysis of extensible die clinched joints in the dissimilar metal sheets combinations of titanium sheet material and aluminum sheet material. Kascak et al. (2017) focused on the wear of the clinched die cavity used for joining microalloyed hot-dip galvanized advanced high-strength steel sheets $\mathrm{H} 220 \mathrm{PD}+\mathrm{Z}$, they also compared the experimental data with the FEA numerical simulation results to substantiate the fact that the dominant part of wear is localized in the radius area surrounding the die cavity. Lei et al. (2018) studied the failure fractures of clinch-bonded hybrid joints for similar and dissimilar copper alloy, aluminium alloy and galvanised steel sheets by a scanning electron microscope (SEM) to characterise the different failure modes. Atia and Jain (2018) developed an axisymmetric finite element (FE) model to simulate die-less clinching experiments and predict the joint strength in shear and peel failure modes.

Foam metal is a new type of structural material that has excellent metal and non-metal characteristics such as, low metal density, high material stiffness, excellent energy-absorption, good damping capacity, and low 
thermal conductivity. For these reasons, it is increasingly being used in the general industrial field (Crupi et al., 2011). When foam metal is used as the structural component, it is usually sandwiched between the dense metal sheets. The resulting compound structure is relatively light and has a high strength. Foam metal can also be used to reduce vibration of the component. In this manner, the optimal mechanical properties under a certain load can be achieved based on the excellent characteristics of the foam metal (Raj and Ghosn, 2007).

Fatigue failure is the most common failure form in mechanical connection parts and fretting wear is now known to be a major cause of fatigue failure in a large number of critical parts. Fretting wear refers to the mechanical damage due to small amplitude vibrations between two metal components, the surfaces of which are pressed against each other. Fretting wear is common in engineering applications such as the mechanical industry, aerospace vehicles, and transportation vehicles. The first real study of fretting wear was conducted by Tomlinson (1927), who designed a device to achieve a slight rotational motion and observed brown iron oxide wear debris on the surface of the steel specimen surface. He called this phenomenon "fretting corrosion". Li et al. (2008) pointed out that fretting wear is the main cause of riveting fatigue failure. Wu et al. (2015) recently studied the fretting fatigue performance of Ti-1023 titanium alloy under different contact pressures, performed scanning electron microscopy (SEM) analysis on fatigue fracture and fretting wear debris, and explored the relationship between crack initiation zone depth and fretting fatigue strength. Hattori et al. (2011) studied the mechanism of fretting wear under the influence of various factors such as contact pressure, external cyclic stress, and micro-motion contact shape. They proposed various methods for predicting the fretting fatigue life. He et al. (2015) found that fretting wear not only accelerated the expansion of fatigue cracks in SPR joints but also changed the direction of crack expansion. Xing et al. (2014) performed element analysis on the fretting wear debris on an aluminium-alloy SPR joint and found that the black wear debris was mainly $\mathrm{Al}_{2} \mathrm{O}_{3}$.

Current research on clinching technology is mainly focused on the feasibility of moulding between similar or dissimilar metal materials and the static properties of joints. The study of the dynamic properties and fretting fatigue in clinched joints is still in its infancy, and there is little research on fretting wear in clinched joints. The extant research shows that the fretting wear of clinched joints is closely linked to the generation of fatigue cracks. However, there is still a lack of research on the fretting wear mechanism and the ways to reduce fretting wear. At this point, no fatigue testing has been reported on clinched structures incorporating a foam metal layer. Consequently the influence of a foam metal layer on fretting wear is still unknown.

In the research reported here, clinched joints were formed in aluminium-alloy-aluminium-alloy and aluminium-alloy-foam-copper-aluminium-alloy sheet samples. Two configurations were assembled for each material combination, single-lap joints for static tests of tensile-shear strength and cross-lap joints for static tests of peeling strength. In addition, fatigue tests were performed on the single-lap joints to analyse the effect of the foam copper interlayer on the fatigue properties of the aluminium-alloy clinched joint. SEM and energy 
spectrometry were used to observe the fracture failures of the two joints and explore the fretting wear failure mechanism.

\section{Experimental Procedure}

\subsection{Materials}

Al5052 aluminium alloy samples $110 \times 20 \times 1.5 \mathrm{~mm}$ in size were used as the upper and lower components on which mechanical tests were performed using a material test system. The mechanical properties of the sheet materials are presented in Table. 1. The foam metal material used in the sandwich clinched joints was copper foam $20 \times 20 \times 1.5 \mathrm{~mm}$ in size; its performance parameters are shown in Table. 2 .

Table 1. Mechanical properties of sheet materials

\begin{tabular}{|c|c|c|c|c|}
\hline Materials & $\begin{array}{c}\text { Tensile } \\
\text { strength }(\mathrm{MPa})\end{array}$ & $\begin{array}{c}\text { Yield } \\
\text { strength }(\mathrm{MPa})\end{array}$ & $\begin{array}{c}\text { Young's } \\
\text { modulus (GPa) }\end{array}$ & Elongation (\%) \\
\hline $\mathrm{A} 15052$ & 233 & 206 & 70 & 12 \\
\hline
\end{tabular}

Table 2. Performance parameters of copper foam

\begin{tabular}{ccccc}
\hline Materials & porosity & Open-cell rate $/ \%$ & Volume density $/ \%$ & Void content $/ \%$ \\
\hline Copper foam & 90 & 98 & 0.45 & 95 \\
\hline
\end{tabular}

\subsection{Specimen and preparation}

In the clinching process, the upper sheet is forced by the punch to flow onto the lower sheet that is supported by an extensible die (Fig. 1, below). The upper and lower sheets then undergo plastic deformation to form a mechanically interlocking structure, which is the clinched point shown in Fig. 2(a) and (b).
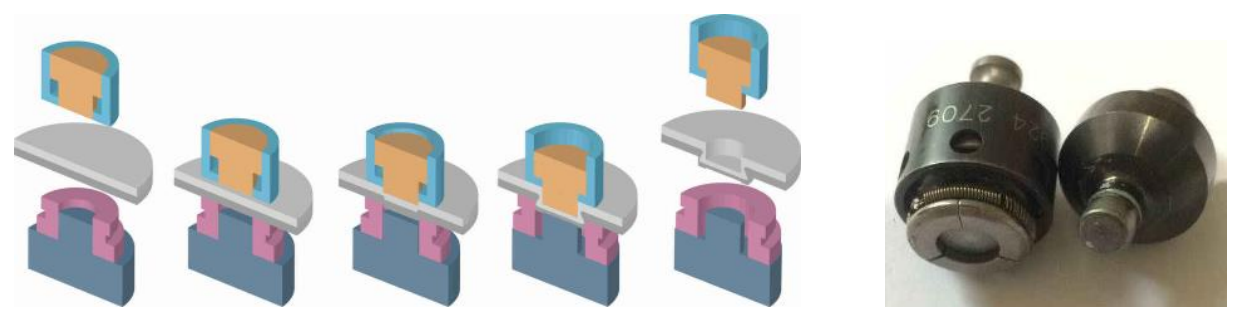

Fig.1 Forming process of clinching and extensible dies

When foam metal is used as a structural component, it is usually placed in such a way as to reduce the vibration of the component. As shown in Fig.2(c) and (d), the copper foam interlayer was added in the lap area 
of $20 \times 20 \mathrm{~mm}$ between the dense metal sheets to build sandwich structure clinched joint.

Four types of specimens were prepared in clinched and sandwich clinched joints, as shown in Fig. 2, and named in Table 3, below. SAA and SCA joints were used in the tensile-shear tests, and XAA and XCA joints were used in the peeling tests. The specimens were clinched with a lap area of $20 \times 20 \mathrm{~mm}$ using a clinching machine and the clinched joint was located at the geometric centre of the lap area.

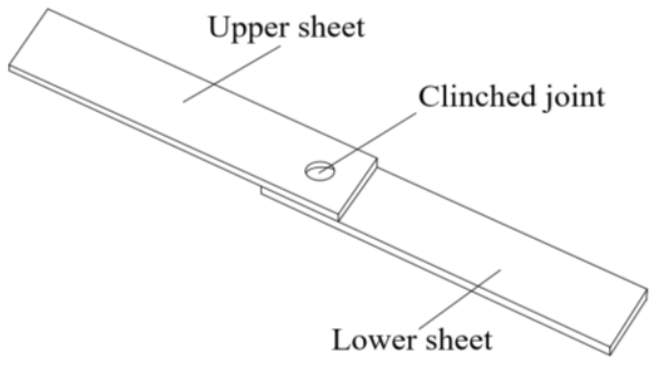

(a) SAA



(c) SCA

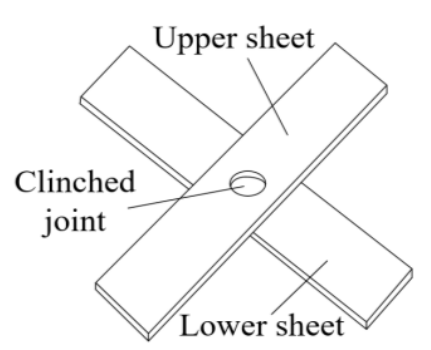

(b) XAA

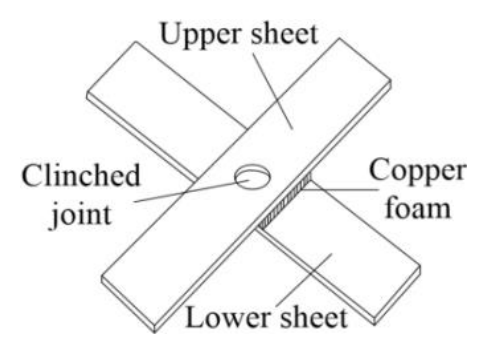

(d) XCA

Fig. 2. Configuration of specimens

Table 3. Combination of specimens

\begin{tabular}{clcc}
\hline Nomenclature & Upper and lower sheets & Sandwich interlayer & Configuration of specimens \\
\hline SAA & Al5052 aluminium alloy & $/$ & Single-lap joints \\
XAA & Al5052 aluminium alloy & $/$ & Cross-lap joints \\
SCA & Al5052 aluminium alloy & Copper foam & Single-lap joints \\
XCA & Al5052 aluminium alloy & Copper foam & Cross-lap joints \\
\hline
\end{tabular}

\subsection{Joints quality assessment}

There are two important parameters in the clinched joint cross-section: the neck thickness $\left(\mathrm{t}_{\mathrm{N}}\right)$ and the undercut $\left(\mathrm{t}_{\mathrm{U}}\right)$ produced in the clinching process (see Fig. 3, below). Generally, they are the main factors influencing the strength of clinched joints. There are some variables of joint parameters that affect the formation of the joint, including punch diameter and chamfer, die diameter and depth, and the connection pressure. After many connection feasibility and process optimization tests, the punch used was SR5207(a round punch 52 mm in diameter with a $0.7 \mathrm{~mm}$ chamfer), the die used was SR60310(a round die $60 \mathrm{~mm}$ in diameter and $10 \mathrm{~mm}$ depth and three extensible valves). The working pressure was 0.6 $\mathrm{MPa}$. 
The single-lap and cross-lap clinched joints have the same forming and cross-section parameters. Therefore, the cross-section parameters of XAA and XCA could be obtained based on those of SAA and SCA.

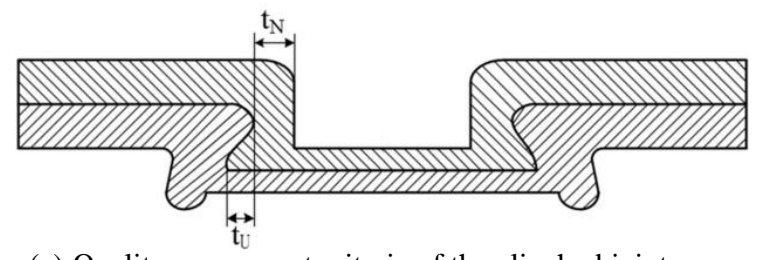

(a) Quality assessment criteria of the clinched joint

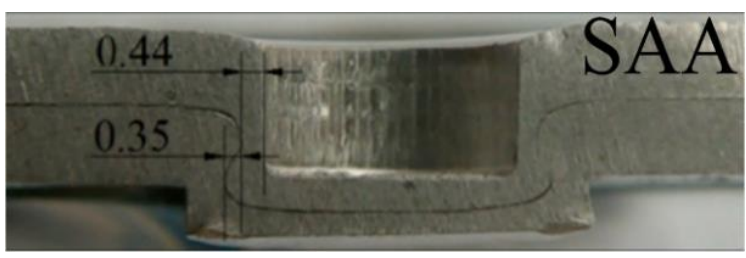

(b) Cross-section of SAA

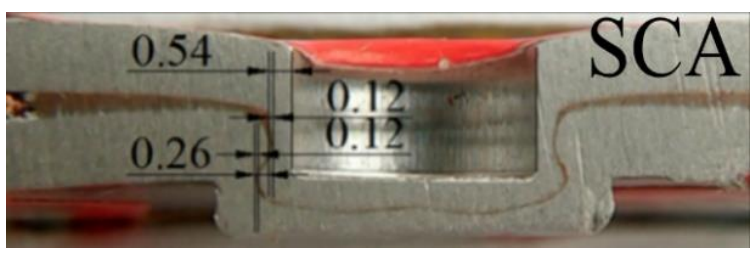

(c) Cross-section of SCA

Fig. 3. Quality assessment criteria of clinched joint

The cross-section parameters of the SAA and SCA clinched joints are shown in Fig. 3. For the SAA joint, the neck thickness $\mathrm{t}_{\mathrm{N}}$ was $0.44 \mathrm{~mm}$, and the undercut $\mathrm{t}_{\mathrm{U}}$ was $0.35 \mathrm{~mm}$. Similarly, $\mathrm{t}_{\mathrm{N}}=0.54 \mathrm{~mm}$, and $\mathrm{t}_{\mathrm{U}}=0.26$ $\mathrm{mm}$ for the SCA joints. The 1.5-mm foam copper was compressed to $0.12 \mathrm{~mm}$ at the clinched joints. The clinched joints had a neck thickness and undercuts, and there was no visible crack. The quality of the clinched joint forming was considered to be acceptable.

As compared to the $t_{N}$ and $t_{U}$ of the SAA clinched joint, the $t_{N}$ of the SCA sandwich clinched joint was larger, and $\mathrm{t}_{\mathrm{U}}$ was smaller, which means that the SCA joints would provide greater neck strength and a lower interlocking force during the tensile-shear and peeling tests. If the thickness of the foam copper is subtracted from $t_{N}$ and $t_{U}$ of SCA to obtain the neck thickness $t_{N 1}$ and the undercut $t_{U 1}, t_{N 1}$ of the SCA sandwich clinched joint is $0.42 \mathrm{~mm}$, which is similar to the value $(0.44 \mathrm{~mm})$ for $t_{N}$ in the SAA clinched joint. However, $t_{U 1}$ is reduced owing to the addition of the foam copper. This is because the foam copper in the "sandwich" clinched structure had a certain resistance to the plastic deformation of the metal during the forming process, resulting in an insufficient metal flow and a corresponding reduction in the undercut.

\section{Results and discussion}

\subsection{Static testing}

A quasi-static downward displacement load was exerted to specimens for static testing. The static tests were performed at a displacement rate of $10 \mathrm{~mm} / \mathrm{min}$ and terminated when the specimen's individual sheets separated or the tensile load decreased to $5 \%$ of the peak load. Specimens of two configurations, single-lap joints for 
tensile-shear strength and cross-lap joints for peeling strength, were designed to discuss the effect of the foam copper interlayer on the static properties of the aluminium alloy clinched joints.

The single-lap joints were clamped directly onto the upper and lower chucks of the materials test machine for the tensile-shear tests. Two spacers having a thickness of $1.5 \mathrm{~mm}$ were added at either end of the specimens to reduce the impact of additional bending. The cross-lap joint was subjected to a peeling test using a holder as shown in Fig. 4. The upper and lower ends of the holder were clamped onto the chuck of the materials test machine.

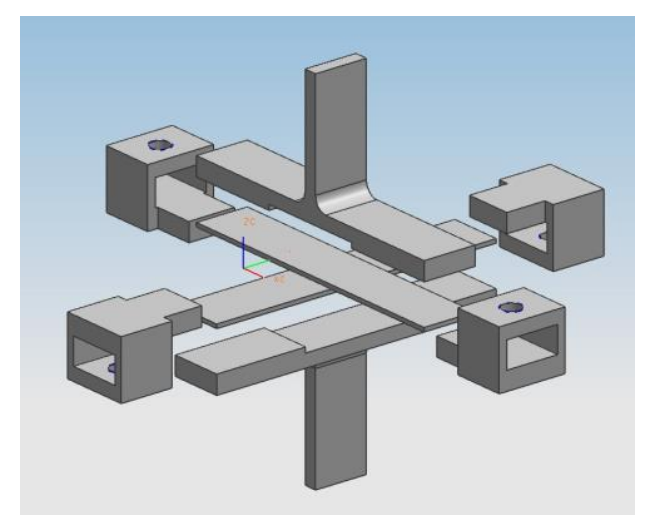

Fig. 4. Holder for cross-lap specimen

The results of the tensile-shear tests are shown in the Table 4. The maximum static load was used as the sample data for statistical analysis.

Table 4. Primary data of the maximum static load for the joints (Unit: N)

\begin{tabular}{ccccc}
\hline Nomenclature & SAA & SCA & XAA & XCA \\
\hline 1 & 1453 & 1545 & 1229 & 1368 \\
2 & 1421 & 1550 & 1271 & 1205 \\
3 & 1466 & 15516 & 1204 & 1288 \\
4 & 1455 & 1557 & 1146 & 1277 \\
5 & 1503 & 1540 & 1251 & 1303 \\
6 & 1464 & 1571 & 1274 & 1271 \\
7 & 1498 & 1524 & 1323 & 1355 \\
8 & 1510 & 1558 & 1095 & 1338 \\
Average load & 1472 & 1550 & 1224 & 1281 \\
Standard deviation & 30 & 14 & 74 & 53 \\
\hline
\end{tabular}

The results were evaluated by using the Lilliefors test for normal distribution, and the Matlab normfit parameter-estimation function, with a $95 \%$ confidence level in each group. The results show that the mean and standard deviation of the experimental results met the requirements of the confidence interval, indicating that 
the data is valid. In addition, it can be seen that the data are consistent from the standard deviation of the four sets of data.

The load-displacement curves for the SAA, XAA, SCA, and XCA joints are shown in Fig. 5. The graphs show an initial stage of linear displacement, indicating elastic deformation. This was followed by non-linear displacement, indicating plastic deformation. This behaviour is mainly related to the material properties. With the gradual increase in displacement, the joints deformed plastically until the maximum load was reached. The weakest point of the joint was then destroyed. The load then rapidly reduced until the joint failed completely. All four types of joints tore at the neck of the upper sheet, and the failure modes were all neck fracture failures (see Fig. 6, below).
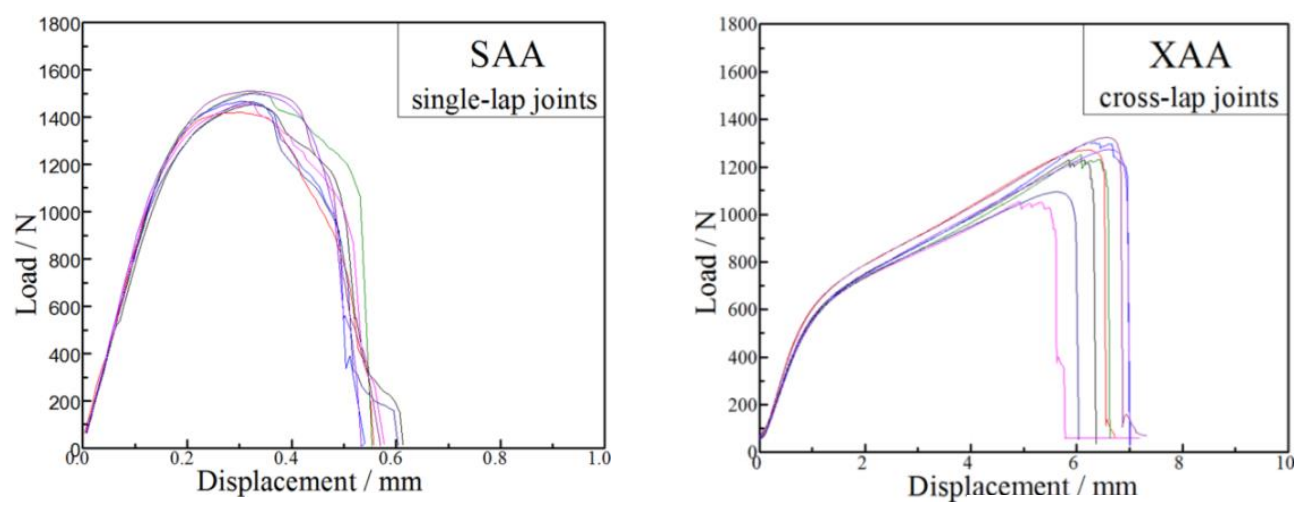

(a) $\mathrm{SAA}$

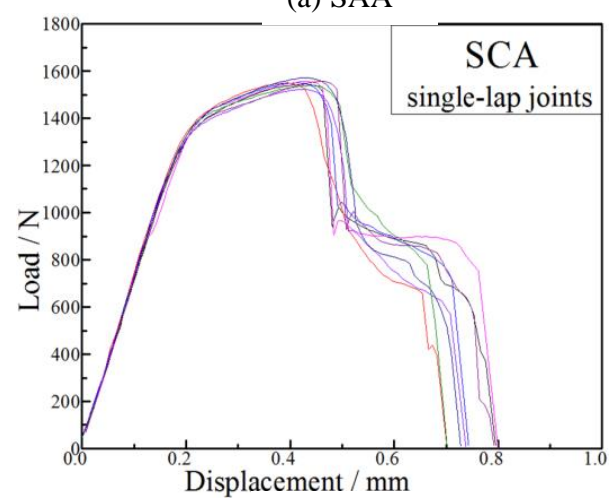

(c) SCA

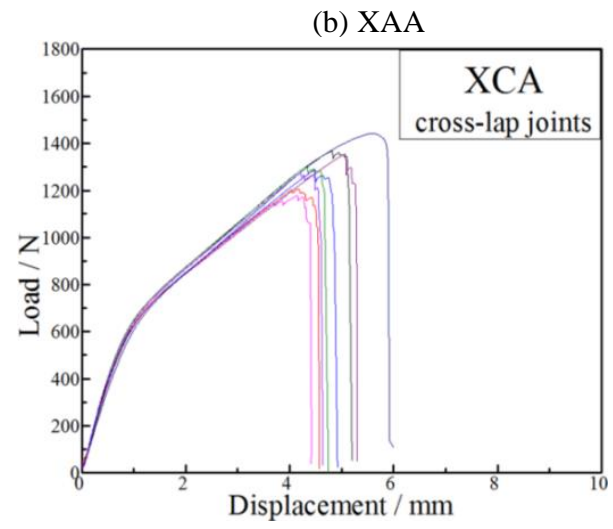

(d) XCA

Fig. 5. Load-displacement curves of joints

The average peak load on the SAA joints was $1471.56 \mathrm{~N}$, and the mean value of the failure displacement was $0.57 \mathrm{~mm}$. With the continuous application of the tensile-shear force, the neck of the upper sheet was plastically deformed until it tore, and the joint load then dropped gradually from maximum load to zero. The average load of the SCA sandwich joint was $1549.58 \mathrm{~N}$, and the mean value of the failure displacement was $0.77 \mathrm{~mm}$. When the load was greater than the strength of the neck provided by the upper sheet and foam copper, the neck began to fail, and the load immediately reduced. Friction at the foam copper interlayer slowed, the decline and the tensile displacement increased significantly. The load dropped sharply as the copper foam was 
broken.

The shear strength of the joint is usually determined by the thickness of the neck in the clinched joint. A comparison of the load-displacement curves in Figs. 5(a) and (c), shows that the addition of the foam copper interlayer significantly reduced the tearing speed at the neck of clinched joint. The shear strength of the clinched joint was effectively increased by $5 \%$, and the shear failure displacement was increased by $35 \%$.

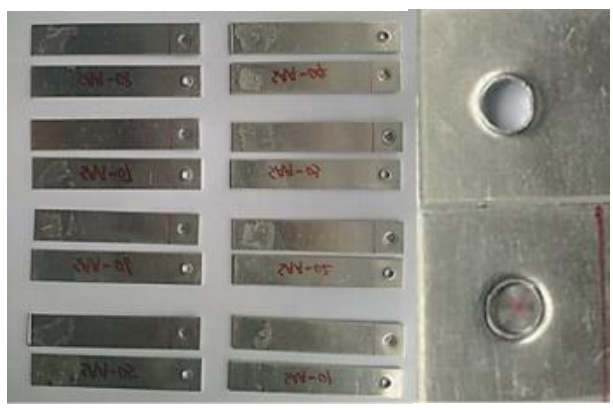

(a) SAA

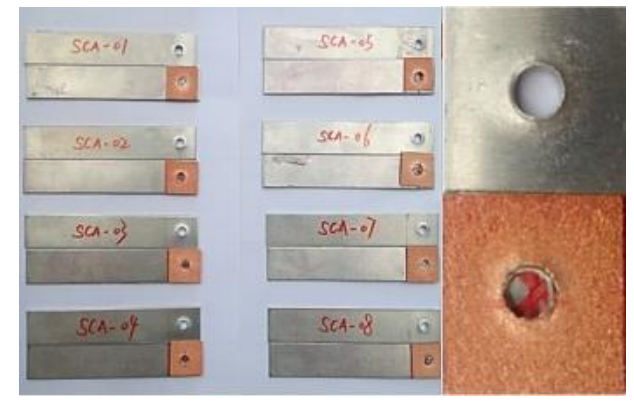

(c) SCA

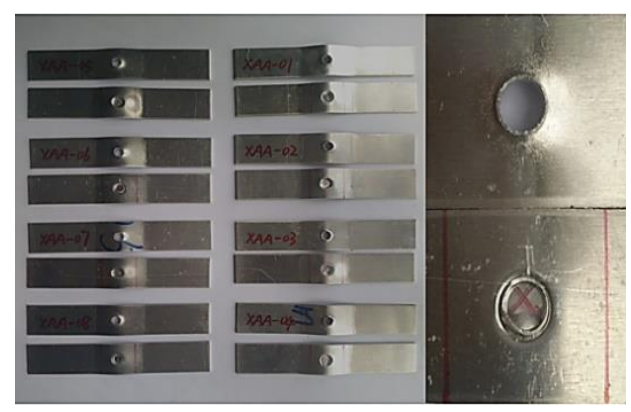

(b) XAA

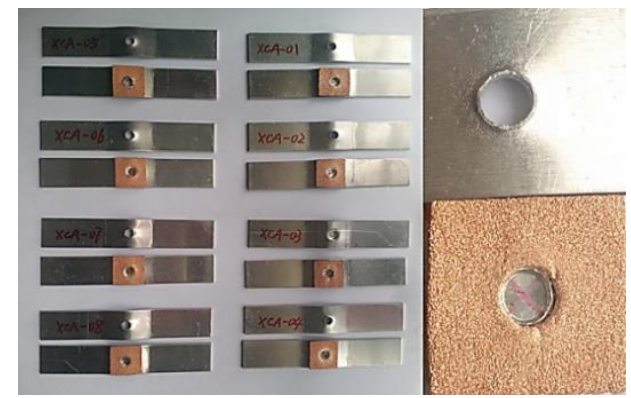

(d) XCA

Fig. 6. Failure mode of joints

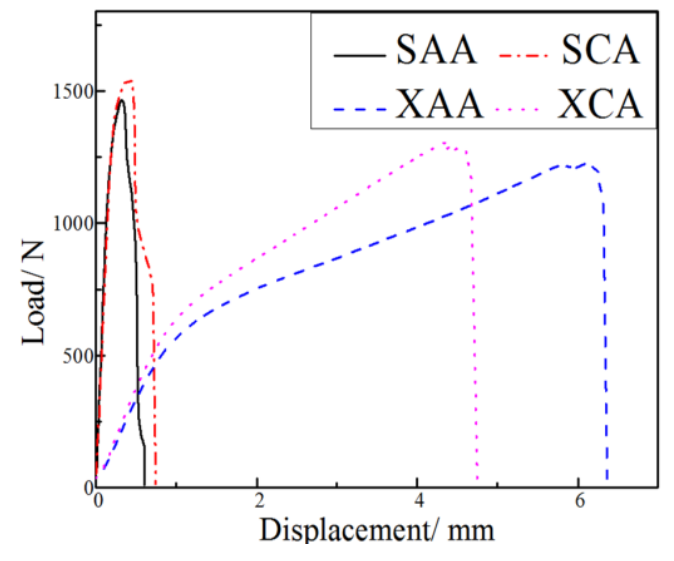

(a) The load-displacement curves

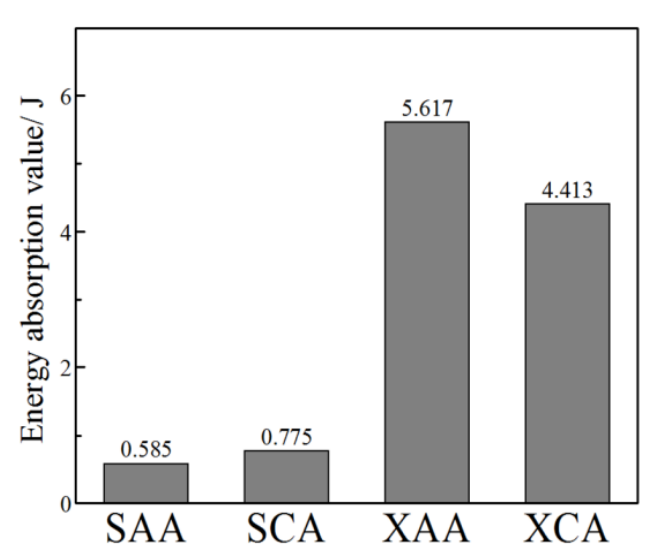

(b) The energy absorption values

Fig. 7. The results comparison of four kinds of joints

The average peak strength of the XAA joints was $1224.13 \mathrm{~N}$, and the average value of the failure displacement was $6.73 \mathrm{~mm}$. When the peeling force was acting on the cross-lap joints, the clinched point and the lap sheet deformed together with the increase in the tensile displacement. The upper and lower sheets of the 
lap area exhibited bending deformation, and the load increased steadily until the neck fractured. The load then dropped to zero. The average peel strength of the XCA sandwich joint was $1281.16 \mathrm{~N}$, and the cross-lap joint failure displacement was $4.62 \mathrm{~mm}$. The peeling strength of the clinched joint is mainly determined by the mechanical interlocking force, which is proportional to the amount of the joint forming undercut. It can be observed from sub-section 2.3 that the undercut of the XCA joint was reduced, and the mechanical interlocking force was also decreased. However, the foam copper interlayer caused an increase in the friction of the interlocking structure at the clinched joint. The load-displacement curve of Figs. 5(b) and (d) shows that the incorporation of the foam copper interlayer reduced the peeling failure displacement of the aluminium-alloy clinched joint by $46 \%$ but had little effect on the peeling strength.

The energy absorption value is a comprehensive parameter reflecting the bearing capacity of the joint and is defined as the area enclosed by the load-displacement curve and the coordinate axis. The carves in Fig. 7(a) show that the cross-lap joints sustained larger tensile displacements than the single-lap joint. This was because of differences in the deformation of the sheet resulting from differences in the configuration of the joint lap. The cross-lap joint has a greater capacity for energy absorption. The incorporation of the foam copper interlayer increased the capacity for energy absorption of the aluminium-alloy clinched joint under the application of a shear force by $33 \%$, but significantly reduced the energy absorption capacity under a peeling load by $27 \%$.

\subsection{Fatigue Behaviour}

The single-lap joints used in the fatigue tests were of the same configuration and dimensions as those used in the static tests. As in the static test, two corresponding spacers were clamped at both ends of the single-lap specimens to reduce the impact of misalignment. The fatigue load ratio was 0.1 , and the frequency was $20 \mathrm{~Hz}$. In the fatigue tests, the specimens were subjected to a sinusoidal waveform, axial load in the pull-pull mode. The failure criterion for the tests was the appearance of visible cracks.

In the research reported here, three levels of fatigue load were considered, and three joints were tested at each level. The validity of the obtained fatigue data was then verified. The fatigue data sets were small because running the fatigue tests is time-consuming. For the finiteness of the testing data, the two-parameter Weibull distribution was used to test the validity of the data, and the shape parameters and corresponding scale parameters of the fatigue life at each load level were calculated as shown in Table 5, below. The results of the analysis show that all the scale parameters were larger than the respective fatigue life, and the data of the joints under each fatigue load level are valid. 
Table 5. Fatigue life statistics

\begin{tabular}{ccccc}
\hline \multirow{4}{*}{ SAA } & Fatigue load level & $87 \%$ & $60 \%$ & $55 \%$ \\
\cline { 2 - 5 } & Stress value/kN & 1.282 & 0.878 & 0.810 \\
& Average life & $2.766 \mathrm{E}+5$ & $6.115 \mathrm{E}+5$ & $1.587 \mathrm{E}+6$ \\
& Coefficient of variation & 0.089 & 0.150 & 0.276 \\
& Shape parameter & 13.454 & 8.014 & 4.345 \\
& Scale parameter & $2.874 \mathrm{E}+5$ & $6.492 \mathrm{E}+5$ & $1.743 \mathrm{E}+6$ \\
\hline \multirow{3}{*}{ SCA } & Fatigue load level & $89 \%$ & $88 \%$ & $80 \%$ \\
\cline { 2 - 5 } & Stress value/kN & 1.383 & 1.358 & 1.247 \\
& Average life & $4.908 \mathrm{E}+5$ & $8.112 \mathrm{E}+5$ & $2.229 \mathrm{E}+6$ \\
& Coefficient of variation & 0.133 & 0.239 & 0.229 \\
& Shape parameter & 8.999 & 5.020 & 5.231 \\
& Scale parameter & $5.182 \mathrm{E}+5$ & $8.833 \mathrm{E}+5$ & $2.422 \mathrm{E}+6$ \\
\hline
\end{tabular}

Based on the three-parameter empirical formula: $\mathrm{N}(\mathrm{S}-\mathrm{S} 0)^{\beta}=\alpha$ (Gao et al., 1987) for processing the experimental data. The fitting equation of the $\mathrm{F}-\mathrm{N}$ curve of the SAA and SCA joints were calculated as $\operatorname{lgN}=$ $5.3044-0.4315 \operatorname{Lg}(\mathrm{S}-0.8016)$ and $\lg \mathrm{N}=7.6777-13.7584 \mathrm{LgS}$, respectively, and the linear correlation coefficients were -1.00 and -0.98 , respectively. The F-N curves are plotted as shown in Fig. 8.

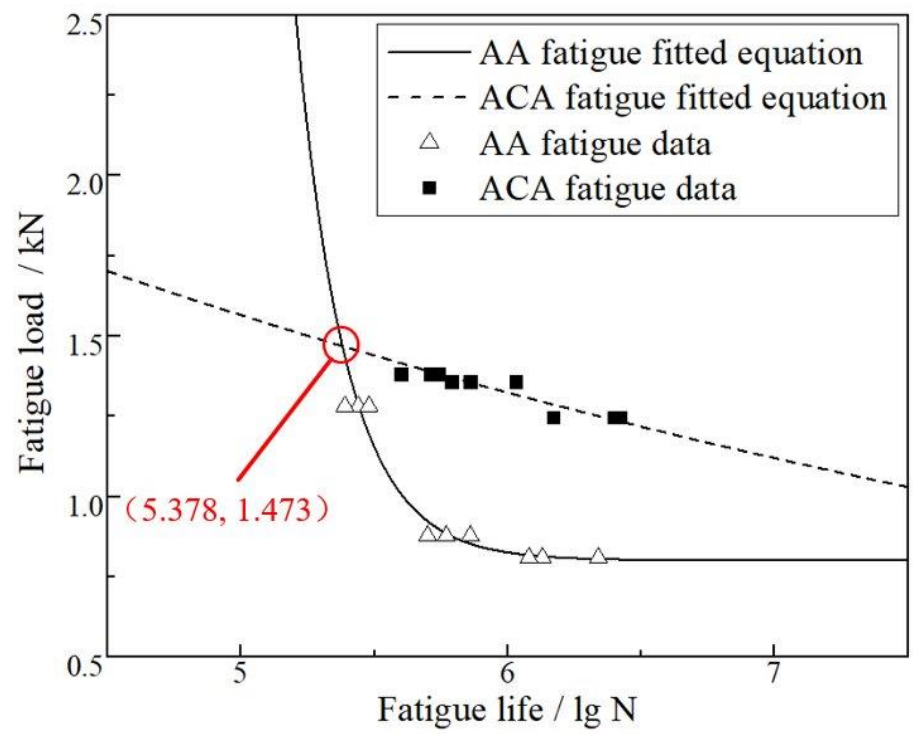

Fig. 8. F-N curves of joints

To explore the trend of the fatigue life of the two groups of specimens under extreme conditions, the F-N curves were extrapolated. If the fatigue load exceeds the yield strength of the joint, the joint fails immediately. Therefore, only the part of the $\mathrm{F}-\mathrm{N}$ curve that is lower than the yield strength was analysed in the fatigue life analysis. According to sub-section 3.1, the average static strengths of the SAA joints and SCA joints were 
1471.56 $\mathrm{N}$ and $1549.58 \mathrm{~N}$, respectively.

The two F-N curves intersected at the fatigue load of $1473 \mathrm{~N}$, and so the main analysis was confined to the part below the intersection of the two F-N curves. On comparing the F-N curves of the SAA and SCA joints, it is obvious that the fatigue performance of the SCA joints was significantly better than that of the SAA joint under the allowable static tensile strength. When the joints were subjected to the same amount of fatigue load, the SCA joints exhibited a longer life, thus indicating that the foam copper interlayer improved the fatigue life of the aluminium-alloy clinched joints. When considering the high-load and long-life performance of the SCA joints under a continuous alternating load, the SAA joints were more sensitive to load changes, and the fatigue life of the joints increased significantly from the high-load case to the low-load case. This indicates that the foam copper played a role in shock absorption and buffering in the clinched joints.

\subsection{Fretting wear}

Clinching technology relies on mechanical interlocking between the upper and lower sheets to achieve a connection. Therefore, fretting wear has a great influence on the fatigue strength and fatigue life of clinched joints and is the most important cause of fatigue failure in clinched joints. The fretting wear mechanism commonly means the formation of wear debris and propagation of micro-cracks. Images of samples used in the fatigue experiments (Fig. 9, below) show that the fatigue failure of the SAA group resulted from neck fracture accompanied by tearing of the lower sheet. The fatigue failure of the SCA group resulted from neck fracture only. The fretting wear failure of the aluminium alloy clinched joints occurred at two locations: the contact surface of the two sheets in the lap-area (A position) and the neck of the clinched point (B position), as shown in Fig. 10.
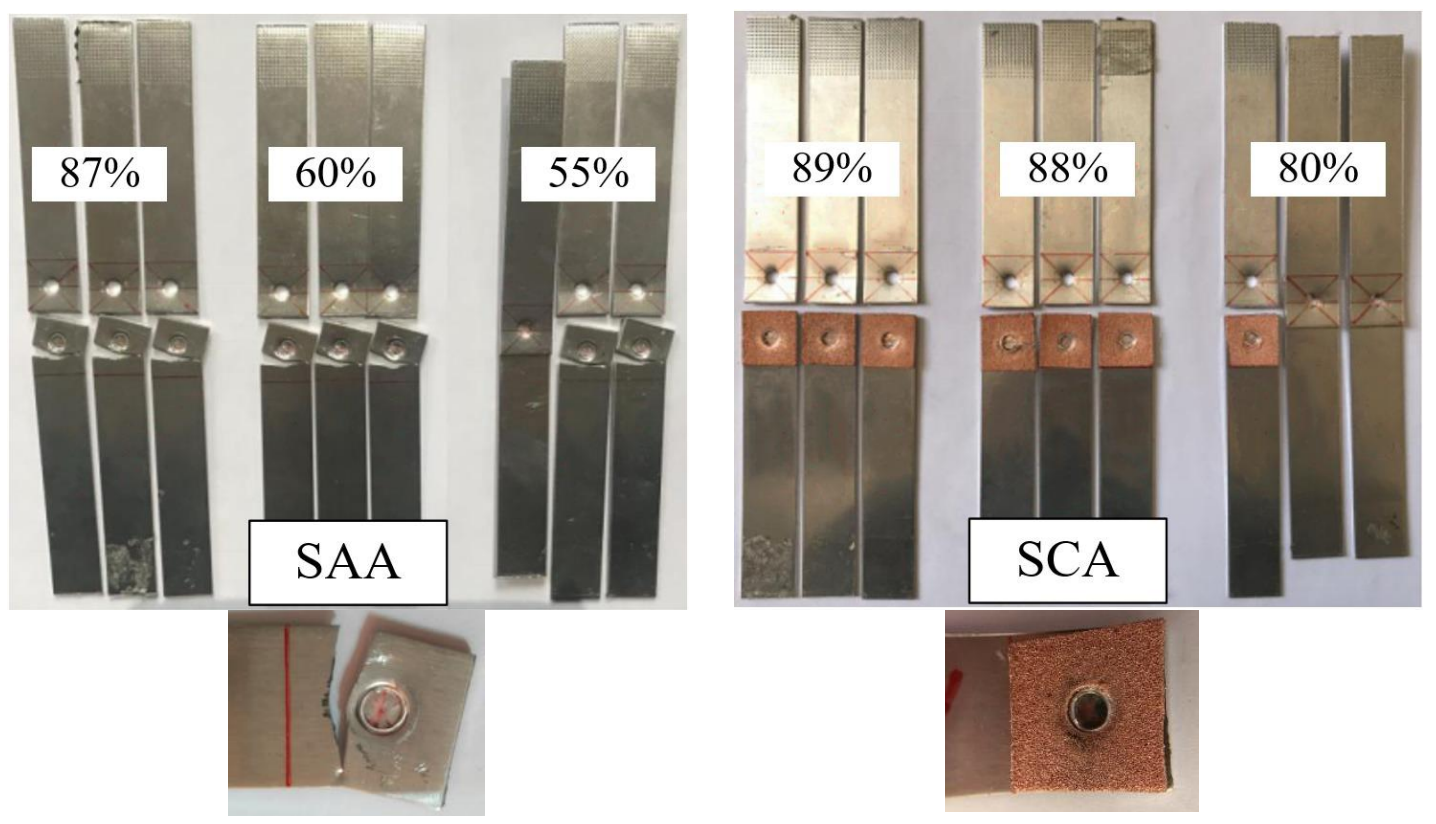

Fig.9 the fatigue experiment results of SAA and SCA clinched joint 


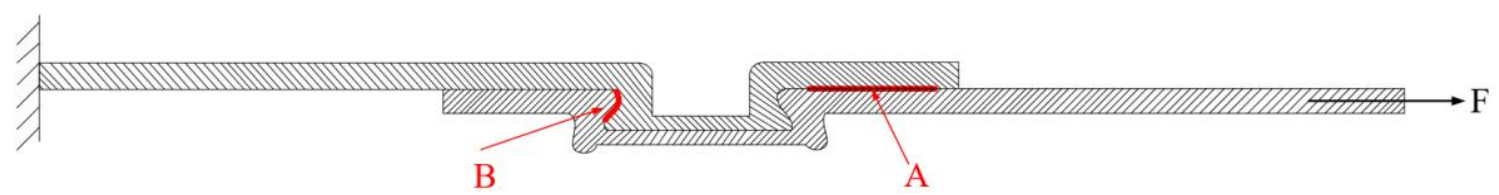

Fig.10 Schematic of clinched-joint fretting-wear position

To further explore the location of fretting wear in two kinds of joint, the fatigue test system was set to stop the fatigue loading when the crack was detected. Then the location of the damage was observed and cross-section analyses of the joints were carried out before the joints were completely broken by the fatigue test.

The image in Fig. 11(a) shows that the SAA joint had a macroscopic crack in the lower sheet around the clinched point. This is where the SAA joint is completely fatigue fractured. The accompanying cross-section of the joint analyzed by electron microscopy clearly shows the sheet fracture and cracks. It can be seen that the fretting wear of the SAA joint occurs mainly in the contact surface of the two sheets in the lap-area (A position). The image in Fig. 11(b) shows that the SCA joint has a crack on the neck side of the clinched point, which is consistent with the position of the neck fracture caused by complete fatigue loading. According to the SEM image of the fracture location, fatigue cracks appeared in the clinched neck and extended from there to the whole neck. The crack fracture zone is a typical crack initiation cleavage from which it can be inferred that the fretting wear of SCA joint mainly occurs in the clinched neck (B position).

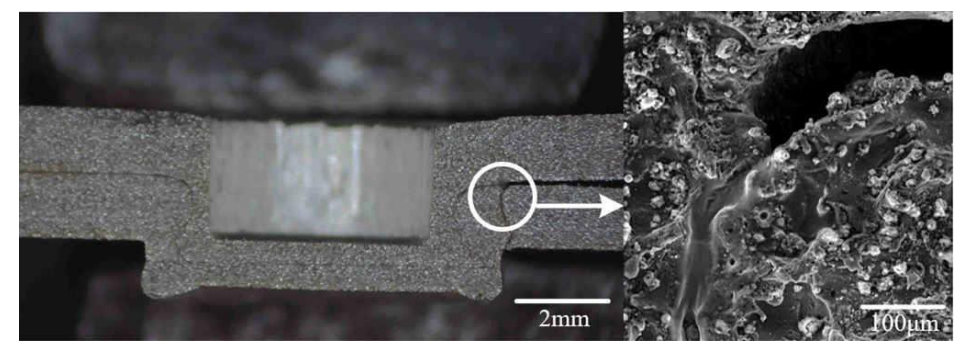

(a) SAA

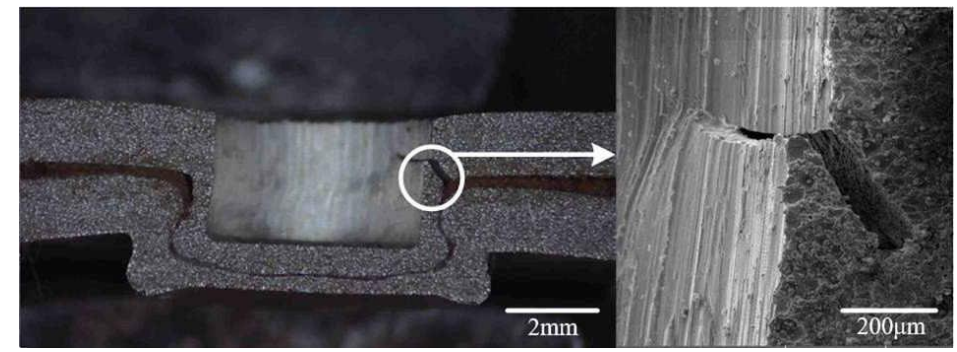

(b) SCA

Fig.11 Damage position and cross-section of joint before the completely fatigue broken

The results show that the addition of foam metal in the clinched joint effectively isolated the fretting wear between the upper and lower sheets. The joint fatigue crack in the SCA joint occurred in the clinched neck, 
which is the weakest part of the joint under the fatigue alternating tensile-shear load. The foam metal interlayer changed the fatigue failure mode of the joint from the lower sheet fatigue fracture for SAA group to the neck fatigue fracture for the SCA specimens.

\subsubsection{Fretting wear mechanism}

The fretting wear failure mechanism in the SAA group of aluminium-alloy clinched joints, was investigated using an FIA NOVA NanoSEM450 SEM and Oxford EDS energy spectrometer. The alternating fatigue load induced a slight relative sliding movement around the clinched point. The tangential movement of the micro-motion surface caused the adhesion of the two surfaces, and the surface material was transferred back and forth between the two surfaces. Finally, wear debris was gradually detached from the matrix, and cracks were produced.
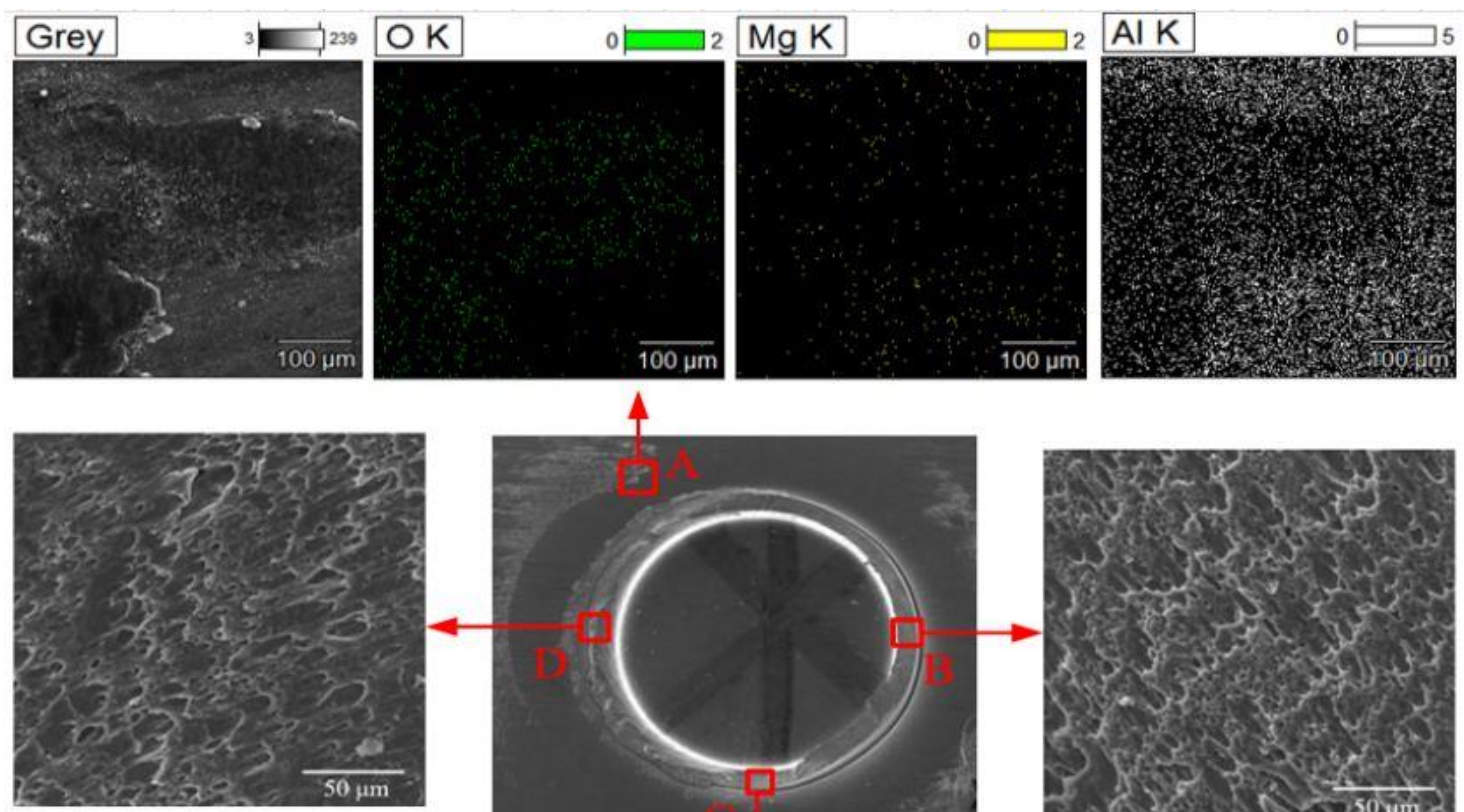

4
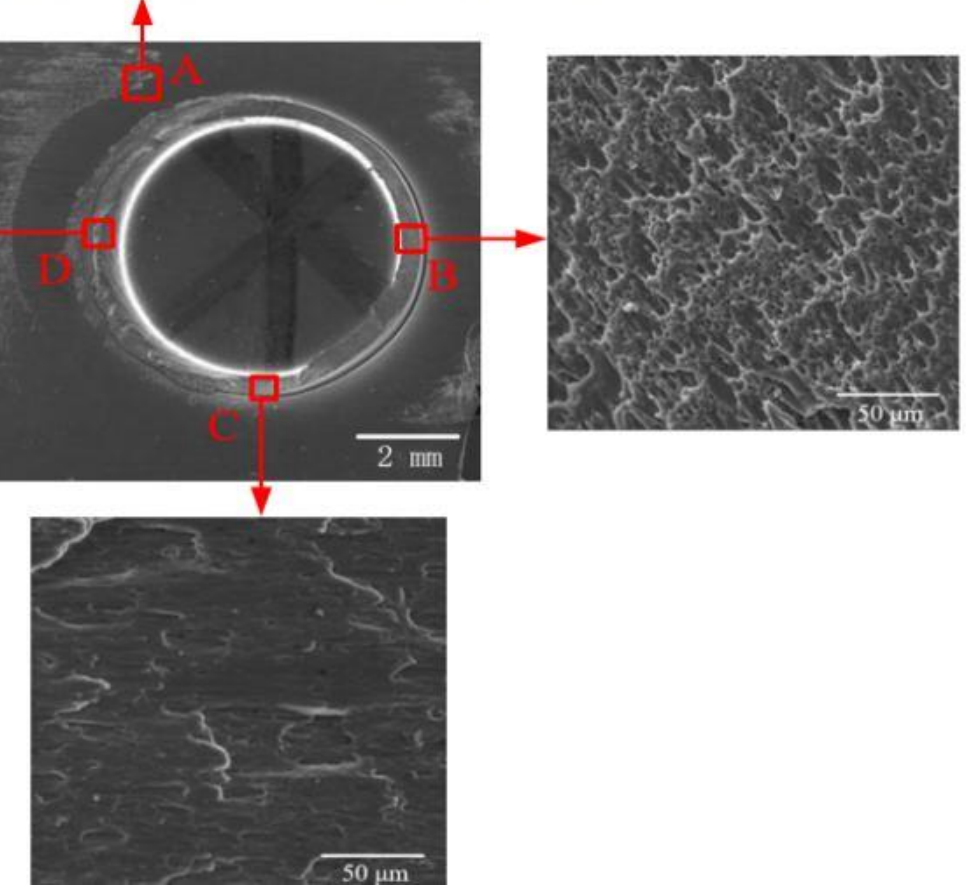

Fig.12 Fatigue failure fracture in the neck of SAA joint

The images in Fig. 12 show that both the neck and the surface of the lower sheet around the clinched point 
have wear debris associated with them, and that the fatigue fracture occurred there. Wear debris from area A was selected for an energy spectrum sweep analysis. It was found that the main components of the wear debris were $\mathrm{Al}, \mathrm{Mg}$, and $\mathrm{O}$. $\mathrm{Al}$ and $\mathrm{Mg}$ are the constituent elements of Al5052 aluminium alloy. The presence of oxygen is due to the oxidation of the metallic elements during the fretting wear process. Areas subjected to fretting wear had greater concentrations of oxygen than areas not subjected to fretting wear. As the hardness of oxidised wear debris is greater than that of the parent metal, the wear debris acted as an abrasive during the fretting process. This aggravated the wear of the parent metal.

An SEM was used to observe the microscopic morphology of the neck fracture of the SAA group specimens. It can be seen in Fig. 12, above that both areas B and D exhibit shear dimples, and that the dimples are small and dense. This indicates that the micro pores inside the material had been fully expanded during the fatigue testing. The micro-structure in area $\mathrm{C}$ is relatively flat and smooth, which indicates that it was torn without excessive plastic deformation. The material at the clinched neck area B was first torn, and the neck was torn along the upper left direction towards both sides, the tear passed through point $\mathrm{C}$. The neck of the clinch joint was completely torn at area D along the lower left direction. No typical fatigue morphology was observed in the entire neck fracture. This indicates that there was no crack source in the neck to cause the joint failure and so it can be inferred that the fretting wear in the neck of the clinched point was not the cause of the joint failure.

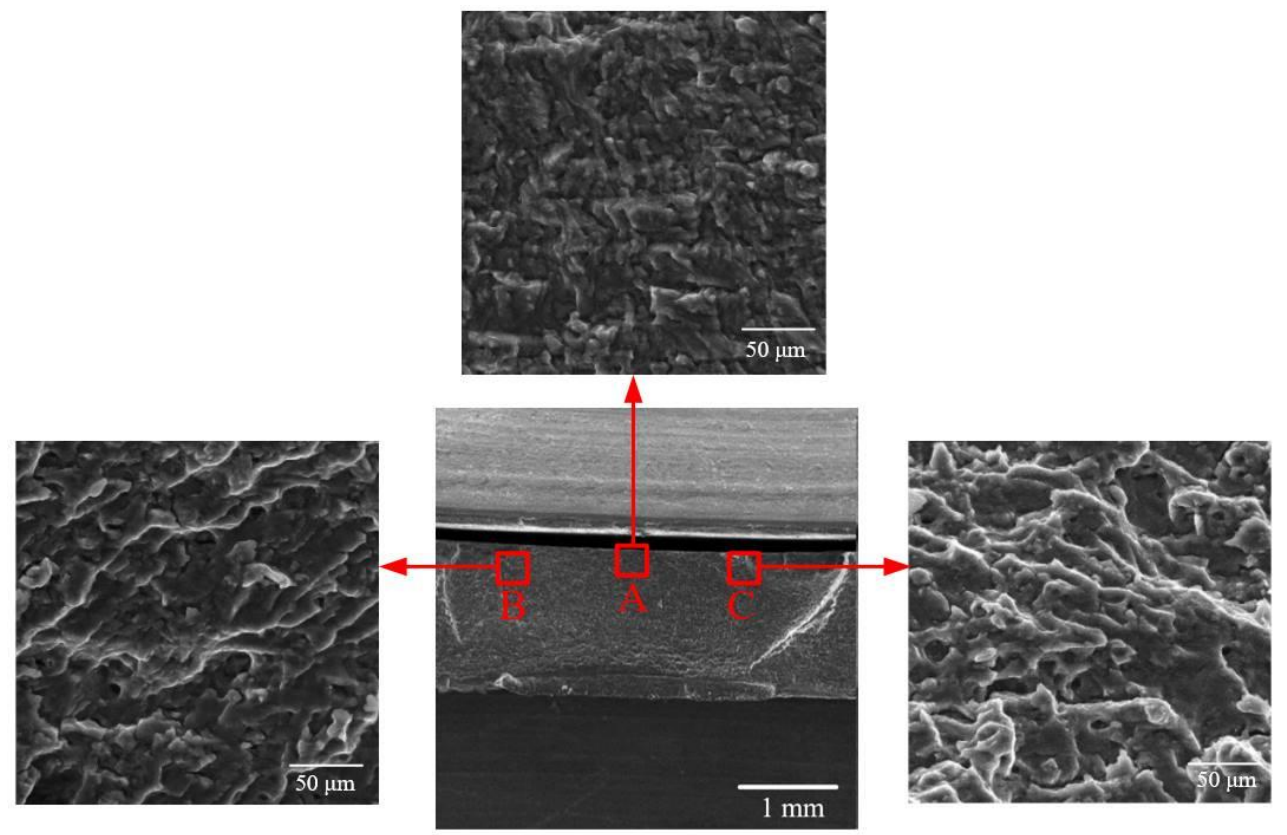

Fig.13 Fatigue failure fracture in upper sheet of SAA joint

An examination of the tear fracture of the lower sheets of the SAA specimens showed that there was a clear crack source and crack extension zone. It can be seen in Fig. 13 that area A showed a cleavage tongue-like topography, which is a typical fatigue source zone feature. The microscopic morphology of areas B and C showed typical fatigue strip morphology and characteristic tear peaks that are typical of the second stage 
characteristic of fatigue crack growth. Moreover, the fatigue strip pointed in the direction of propagation of the crack propagation, indicating that the crack propagated from area $\mathrm{A}$ in the lower sheet near the surface, and then spread to areas B and C along the lower left and lower right directions, respectively. These cracks continued to grow and expand under the cyclic load, and finally caused the lower sheet to tear.

Based on the fatigue fracture analysis of the neck and the lower sheet in the SAA group of specimens, it can be inferred that the fretting wear between the upper and lower sheets caused the generation of oxide wear debris and micro-cracks. The micro-cracks expanded until they caused fretting fatigue failure of the lower sheet. After the failure of the lower sheet, the fatigue load was assumed by the neck of the clinched point. Shortly afterwards, the neck of the clinch joint was completely torn and the SAA joint failed.

\subsubsection{Influence of foamed copper}

To investigate the effect of the foam copper interlayer on the fretting wear of the clinched joint, the fatigue failure of the SCA joint was investigated using an SEM and energy spectrometer for fracture analysis. The image in Fig. 14, SE is the result of a secondary electron scan, showing the microscopic topography. The image in Fig. 14, BSE is the result of a backscattered electron scan and shows the composition contrast of the atoms. The larger the atomic number, the brighter the image.

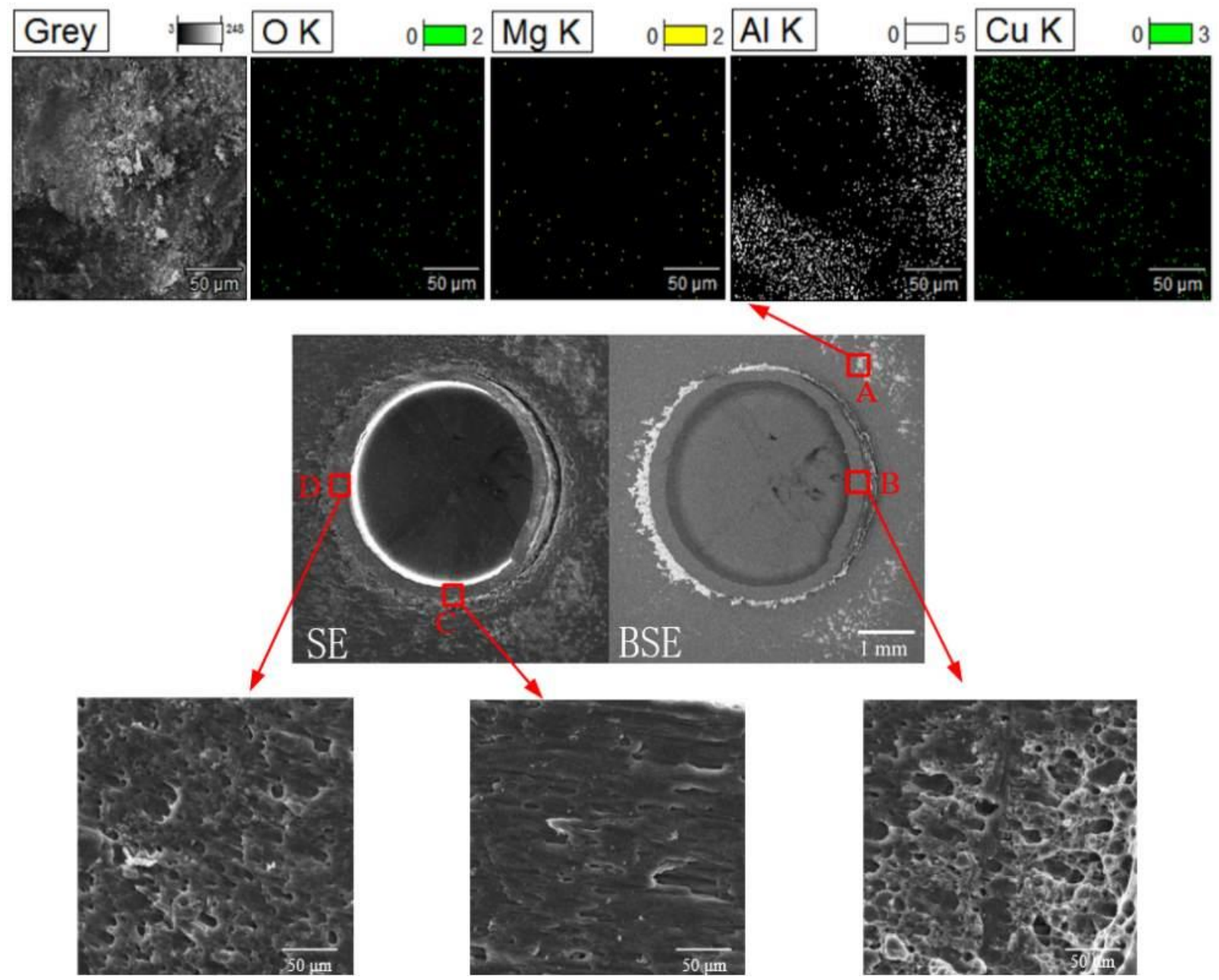

Fig.14 Fatigue failure fracture in neck of SCA joint 
Bright white wear debris can be seen at the neck and around the clinched point in the Fig. 14 BSE image of an SCA joint. The energy spectrum analysis method was used to detect the wear debris component in area A, and it was found that, in addition to the $\mathrm{Al}$ and $\mathrm{Mg}$ elements of the Al5052 aluminium alloy, the main components in the wear debris were $\mathrm{Cu}$ and $\mathrm{O}$ elements. A large amount of $\mathrm{Cu}$ and the different microscopic morphology of foam copper metal before and after the fretting wear shown in Fig. 15 were found, and they fully demonstrated that the foam copper interlayer participated in fretting wear and isolated the direct frictional contact between the upper and lower sheets during the fatigue testing.

The fatigue failure of the SCA joints resulted from neck fracture. The microscopic morphology of the neck fracture was analysed using a SEM. The microscopic morphology at point B in Fig. 14 not only had large and sparse shearing dimples, but also significant fatigue fringe morphology in the right half. This indicates that the fatigue fracture occurred at B and this was the source of the cracks. The microscopic morphology of areas $\mathrm{C}$ and D were similar to that of the failure points in the SAA group, which are short-term static tensile-shear failures caused by the fatigue load after the failure of the other joint parts.

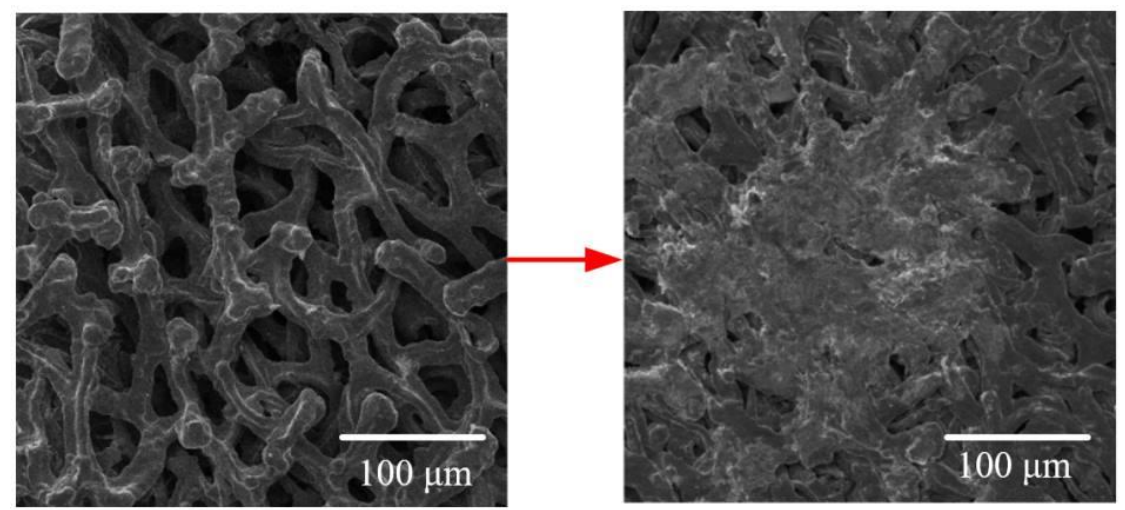

Fig.15 Comparison of foam copper before and after fretting wear

In summary, the foam copper interlayer played a role in isolation and energy absorption in the aluminium-alloy clinched joints. It effectively reduced the fretting wear between the upper and lower sheets and prevented the fretting fatigue failure of the lower sheet. The joint failure mode was changed from the lower-sheet fatigue fracture with neck fracture of the SAA joints to the neck fatigue fracture of the SCA joint. The foam copper interlayer greatly enhanced the fatigue life of the aluminium-alloy clinched joint and effectively improved their fatigue performance.

\section{Conclusion}


1) Including a foam copper layer in clinched joints increased their shear strength by $5 \%$ but had little effect on the peeling strength. It also increased the energy absorption of the joint under a shear force by $33 \%$, but reduced that under a peeling load by $27 \%$.

2) The fatigue performance of the aluminium-alloy-foam-copper-aluminium-alloy sandwich clinched joints was significantly superior to that of the aluminium-alloy-aluminium-alloy clinched joints. The incorporation of the foam copper layer improved the fatigue life of the aluminium-alloy clinched joint.

3) The fretting wear of the clinched joint occurred mainly at two locations: the contact surface of the two sheets in the lap-area and the clinched neck. Fretting wear generated oxide wear debris and micro-cracks on the sheet surface. The micro-cracks continuously expanded until the fretting fatigue failure of the clinched joint occurred.

4) The foam copper interlayer prevented the fatigue fracture of the sheet and effectively enhanced the fatigue life of the aluminium-alloy clinched joint. It did this by reducing the fretting wear between the upper and lower sheets.

\section{Acknowledgments}

This research is supported by National Natural Science Foundation of China (Grant No. 51565023).

\section{Reference}

Atia, M.K.S., Jain, M.K., 2018. Finite element analysis of material flow in die-less clinching process and joint strength assessment, Thin. Wall. Struct. 127, 500-515.

Chen, C., Zhao, S., Han, X., Cui, M., Fan, S., 2016. Optimization of a reshaping rivet to reduce the protrusion height and increase the strength of clinched joints, J. Mater. Process. Technol. 234, 1-9.

Crupi, V., Epasto, G., Guglielmino, E., 2011. Impact response of aluminum foam sandwiches for light-weight ship structures, Metals. 1(1), 98-112.

Gao, Z., Fu, H., Liang, M., 1987. Fitting methods of S-N curves, J. BHXB. 1,115-119.

Hattori, T., Kien, V. T., Yamashita, M., 2011. Fretting fatigue life estimations based on fretting mechanisms, Tribol. Int. 44(11), 1389-1393.

He, X., 2017. Clinching for sheet materials, Sci. Technol. Adv. Mater. 18 (1), 381-405.

He, X., Zhao, L., Deng, C., Xing, B., Gu, F., Ball, A., 2015. Self-piercing riveting of similar and dissimilar metal sheets of aluminum alloy and copper alloy, Mater. Des. 65, 923-933.

He, X., Lei, L., Zhang, Y., Xing, B., 2017. Mechanical Properties and Fracture Analysis of Clinched Joints in Titanium Sheet Materials, Acta. Phys. Pol. A. 131(1), 16-19. 
Kascak, L., Mucha, J., Spisak, E., Kubik, R., 2017. Wear Study of Mechanical Clinching Dies During Joining of Advanced High-Strength Steel Sheets, Strength. Mater. 49(5), 726-737.

Lambiase, F., Ilio, A. D., Paoletti, A., 2015. Joining aluminium alloys with reduced ductility by mechanical clinching, Int. J. Adv. Manuf. Tech. 77(5-8), 1295-1304.

Lei, L., He, X., Zhao, D., Zhang, Y., Gu, F., Ball, A., 2018. Clinch-bonded hybrid joining for similar and dissimilar copper alloy, aluminium alloy and galvanised steel sheets, Thin. Wall. Struct. 131, 393-403.

Li, Y., Tao, C., Zhang, W., Jiang, T., 2008. Fracture analysis on cage rivets of a cylindrical roller bearing, Eng. Fail. Anal. 15, 796-801.

Mucha, J., 2011. The analysis of lock forming mechanism in the clinching joint, Mater. Des. 11(10)(2011) 4943-4954.

Paula, A. A. D., Aguilar, M. T. P., Pertence, A.E.M., Cetlin, P. R., 2007. Finite element simulations of the clinch joining of metallic sheets, J. Mater. Process. Technol. 182(1-3), 352-357.

Raj, S. V., Ghosn, L. J., 2007. Failure maps for rectangular 17-4PH stainless steel sandwiched foam panels, J Mater Sci Eng A. 474(1), 88-95.

Spisak, E., Kascak, L., Mucha, J., 2012. Joining materials used in car body production by clinching, Chem. Listy. 106, S541-S544.

Tomlinson, G. A., 1927. The rusting of steel surface in contact, P. Roy. Soc. 115(1927) 472-483.

Varis, J. P., 2002. The suitability for round clinching tools for high-strength structural steel, Thin. Wall. Struct. 40(3), 225-238.

Varis, J. P., 2003. The suitability of clinching as a joining method for high-strength structural steel, J. Mater. Process. Technol. 132(1), 242-249.

Wu, G., Liu, X., Li, H., Sha, W., Huang, L., 2015. Effect of contact pressure on fretting fatigue behavior of Ti-1023, Wear. 326-327, 20-27.

Xing, B., He, X., Zeng, Z., Wang, Y., 2014. Mechanical properties of self-piercing riveted joints in aluminum alloy 5052, Int. J. Adv. Manuf. Tech. 75, 351-36. 